Research Article

\title{
Implementation of Design-Based Research in Software Engineering Education: A Case of Final Project Course
}

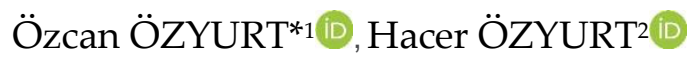 \\ ${ }^{1}$ Karadeniz Technical University, Technology Faculty, Department of Software Engineering, Trabzon, Turkey, oozyurt@ktu.edu.tr \\ ${ }^{2}$ Karadeniz Technical University, Technology Faculty, Department of Software Engineering, Trabzon, Turkey, hacerozyurt@ktu.edu.tr \\ * Corresponding Author: oozyurt@ktu.edu.tr
}

\begin{tabular}{l}
\hline Article Info \\
\hline \\
Received: 25 April 2019 \\
Accepted: 10 June 2019 \\
$\begin{array}{l}\text { Keywords: Design-based research, } \\
\text { engineering education, software } \\
\text { engineering, improving classroom } \\
\text { teaching. }\end{array}$
\end{tabular}

DOI: $10.18009 /$ jcer.557913

Publication Language: English

\begin{abstract}
This study aims to carry out final projects that were designed and coded within the scope of Software Engineering Final Project course in accordance with design-based research and observe the process hereof. Students developed their final projects pursuant to design-based research within the framework of a study that lasted for 8 weeks in total in spring term 2017-2018. Having been developed by relevant researchers, observation and control form were used in the study as data gathering tools. Processes of these projects that were developed via these forms were recorded on a weekly basis. Throughout this study, in which totally 8 students participated and 5 projects were created, the whole process of "Which one is your choice?", a mobile application development project, was described. All stages of design and realization of this project, in which Mobile-D software development method was used, were revealed in detail. This study describes the details of a design-based research process which was operated on a real software project. The findings obtained from the study casts light upon effective utility of this method in project-based courses particularly in software engineering education and generally in engineering education. In addition, the results of this study are especially important in terms of the application of this method to the students in the development of a project or product.

To cite this article: Özyurt, Ö. \& Özyurt, H. (2019). Implementation of design-based research in software engineering education: A case of final project course. Journal of Computer and Education Research, 7 (14), 213-227. DOI: 10.18009/jcer.557913
\end{abstract}

open access (a) Crossmark (c)

\section{Introduction}

Design-Based Research (DBR) attracts attention among innovative approaches in education, as frequently practiced in nowadays. This approach is especially utilized when the process of developing a product or project should be revealed in detail. Studies focusing on processes of designing and developing a product, project, e-learning platform or service design in educational researches are generally brought together under DBRs (Kuzu, Çankaya \& Misirll, 2011). DBR is defined as a systematic and flexible research method aimed at developing context-sensitive design principles and theories whose analysis-designdevelopment and implementation processes are carried out by both researchers and 
participants on a cyclical basis (Amiel \& Reves, 2008; Brown, 1992; Wang \& Hannafin, 2005; Yıldırım, 2014). The most important feature of DBR, which distinguishes it from other educational researches, is its focus on the process and components that must be changed for a better implementation rather than applying and comparing two different methods (Baltac1, Yıldız, Kıymaz \& Aytekin, 2016; Kuzu et al., 2011; Tural-Sönmez, 2017).

To speak philosophically, DBRs are said to be grounded on basic engineering processes (Aşık \& Yılmaz, 2017; Sandoval \& Bell, 2004). In fact, these researches are accepted as researches where analysis-design-implementation-development and evaluation stages are followed and the called processes are reported thoroughly (Reeves, 2000; Wang \& Hannafin, 2005). Moreover, DBRs generally involve developing a product-model-platform for the solution of a problem and meanwhile operating similar processes in engineering discipline (Anderson, Shattuck, 2012; Aş1k \& Yılmaz, 2017; Ercan \& Şahin, 2015; Lesh \& Sriraman, 2005; McKenney \& Reeves, 2013). When it is considered that the ultimate goal of DBRs is to put forth designs and implementations that were optimized in terms of effectiveness, efficiency and applicability, these goals are said to be corresponding to engineering processes (Aşık \& Yılmaz, 2017). Recent increase in DBRs' usage in educational researches is remarkable (Aşık \& Yılmaz, 2017; Baltacı et al., 2016; Collins, Joseph \& Bielaczyc, 2004; Kuzu et al., 2011). However, these studies can be said to be restricted compared to traditional educational researches since the very first difficulty in DBR implementations is timing problem (Aşık \& Yllmaz, 2017). Having said that, various studies that base on DBR are said to be carried out in different fields of educational sciences (Baltac1 et al., 2016; Coşkundere \& Erişti, 2017; Ercan \& Şahin, 2015; Kuzu, Cavkaytar, Çankaya \& Öncül, 2013; Tural-Sönmez, 2017; Yaman, Dönmez, Avcı \& Yurdakul, 2016; Yıldırım, 2014). It may be indicated that the common feature of these studies is their focus on revealing and reporting the process in detail rather than dealing with the academic success.

Even though the rarity of DBRs in educational researches generally attract attention, not much difference can be caught when viewed in terms of engineering education. If we take into account that philosophy underlying DBRs overlap with basic engineering processes (Sndoval \& Bell, 2004), the existence of studies that base on DBR in engineering educational field is of special importance. Among primary goals of engineering education, raising wellsupported students in occupational fields such as design and management of project process is strongly emphasized (Jollands, Jolly, Molyneaux, 2012; Mills \& Treagust, 2003; Zhou, 
2012). Stages of design and project development processes in engineering bear resemblance with the structure of DBRs (Aş1k \& Yilmaz, 2017). When viewed from this perspective, the necessity and importance of different studies on DBR for engineering education in general and software engineering in particular seem blindingly obvious. When looked from the perspective of software engineering education, DBRs are thought to be used effectively in especially project-based application development studies (Özyurt \& Özyurt, 2017). Software life-cycle that consists of operational steps followed to create a software product also bears resemblance to cyclical structure of DBR. Therefore, employing DBRs in especially projectbased courses may enable to put forward the process in detail. In this respect, detailed process of a project which was created during final project course (Software Engineering Department) on DBR implementation was put forward. In other words, DBR was benefitted for the production of final projects through this study and production process of a selected one was described.

\section{Method}

In this section, research model, study group, implementation process and relevant information on this process are included.

\section{Research Model}

This study was carried out in accordance with DBR. New products, theories and applications are developed in DBRs and this process is actualized with the help of collaboration between researcher and participant (Barab \& Squire, 2004; Wang \& Hannafin, 2005). One of the strong dimensions of DBRs is systematic evaluation of products in development stage under actual usage conditions and utilization of these evaluations for improving direct development (Dönmez, Yaman, Şahin \& Kabakçı Yurdakul; 2016). Another superior dimension of DBRs is their favorability for design and development of working and testable products (Coşkundere \& Erişti, 2017). For the study, this method is preferred to describe design and development processes of final projects in detail. 


\section{Study Group}

Study group of this research is comprised of 8 students, who took Final Project course, a last grade lesson of Software Engineering Department in a Turkish university's Technology Faculty.

\section{Implementation Process}

This study was carried out in an 8-week-process within the scope of Final Project course, which is a last grade lesson of software engineering. The aim of this course is to enable students to realize a software project. In the beginning of the course, students decided their final project topics. Students could work individually or in group. Students that participated in the study were coded as Std1, Std2,.., Std8. One of the most prominent elements in DBRs is that research is conducted together with participants. Final project topics are related to daily life and students taking the course also assumed the role of participants for each project. Within this scope, no harm was seen for conducting the study in accordance with DBR. In Table 1, information about students, groups and project topic are given.

$\underline{\text { Table 1. Final project groups and list of topics }}$

\begin{tabular}{|c|c|c|}
\hline $\begin{array}{c}\text { Group } \\
\text { No }\end{array}$ & Students & Name and Short Description of the Project \\
\hline G1 & Std1-Std2 & $\begin{array}{l}\text { Smart SQL Tutor } \\
\text { Within the scope of this project, SQL tutor will be designed and developed as } \\
\text { smart e-learning application. This system, which will be used for learning SQL } \\
\text { known as data processing and questioning language, will feature as a smart } \\
\text { teaching system. Students will be required to write their own SQL queries } \\
\text { against given tasks in the learning platform to be developed. If any, mistakes } \\
\text { shall be detected in the query written by the student and smart clues will be } \\
\text { given to students to remove them. }\end{array}$ \\
\hline G2 & Std3 & $\begin{array}{l}\text { Movie Database Application with NoSQL } \\
\text { This project aims to design and code a movie database application like IMDB } \\
\text { in accordance with NoSql database architecture. Thanks to this platform where } \\
\text { MongoDB is used as database, a database application like IMDB will be } \\
\text { developed. }\end{array}$ \\
\hline G3 & Std4 & $\begin{array}{l}\text { Mobile Demand Management System } \\
\text { This project aims to develop a mobile demand-complaint-suggestion-opinion } \\
\text { management system for any kind of institution/organization. With the } \\
\text { successful realization of the project, a platform through which people convey } \\
\text { the problems they encounter in daily life, their needs or } \\
\text { opinions/suggestions/demands/complaints about any kind of situation to the } \\
\text { relevant institution/organizations in a practical and fast manner and also } \\
\text { relevant institutions can reply quickly will emerge. }\end{array}$ \\
\hline
\end{tabular}




\section{G4 Std5-Std6 Activity/Organization Social Media Application}

A social media application will be developed within the scope of the project. Thanks to this application to be developed, a structure where people doing social activities (running, jogging, cinema, footballing) can gather together will emerge. A lot of people have difficulty in meeting new people with whom they will carry out social activities when they move in another place or take on a vacation. Thus, finding people who will accompany them may take a long time. With the help of this platform, people may organize social activity/organizations, see the existing ones or participate in whatever events they want.

G5 Std7-Std8 Which one is your choice? Mobile Application

People may behave indecisively in daily life when making choices. For example; this case may appear when buying a product, doing a plan for what to wear or where to go for holiday. With this project, a platform that will help users decide through forming a survey and asking different participants' opinions will emerge. Thanks to this platform, user can form a survey by uploading photographs of relevant object or place. With this survey, the user can ask opinions of his/her friends and other users. Thanks to surveys including pictures, users will help other users making decisions.

After deciding their project topics, students made their plans in accordance with software life-cycle and infrastructure researches about software development methodologies and tools to be used by them. Having worked for infrastructure and preliminary drafts for the first two months, students began developing their projects as of third week. Final project course was planned as a 2-hour-course in a week. Students kept on developing their projects in this 8-week period. Having developed their project and their application in extracurricular process, students presented the current version of their own project before all students in course sessions. During these sessions, which were similar to brainstorms, project design was evaluated and recorded via observation and control form by researchers. Weekly process monitoring was carried out for each project about these records. Projects that were developed in course sessions were evaluated on the basis of design problems and relevant solutions and how to reflect these solutions on the design were tried to be determined. Thanks to these sessions, changes and improvements to be conducted on the design were decided. These decisions were recorded via observational method and control form and then appointed as mission. Next week, missions that were completed not completed and to be completed in following week were monitored with the help of this form. And a cyclical structure was created and each project could access an ultimate design without any kind of problem. Shortly, that week's design draft was discussed while the ultimate version of previous interface was confirmed under the rule of this cyclical structure. Accordingly, study 
process was carried out pursuant to cyclical structure of design-based research and ultimate versions of these products emerged. One of the projects was discussed randomly in the part of findings and development process hereof was revealed in detail. Figure 1 summarizes the operation steps of the study conducted in accordance with the design-based research approach throughout the study.

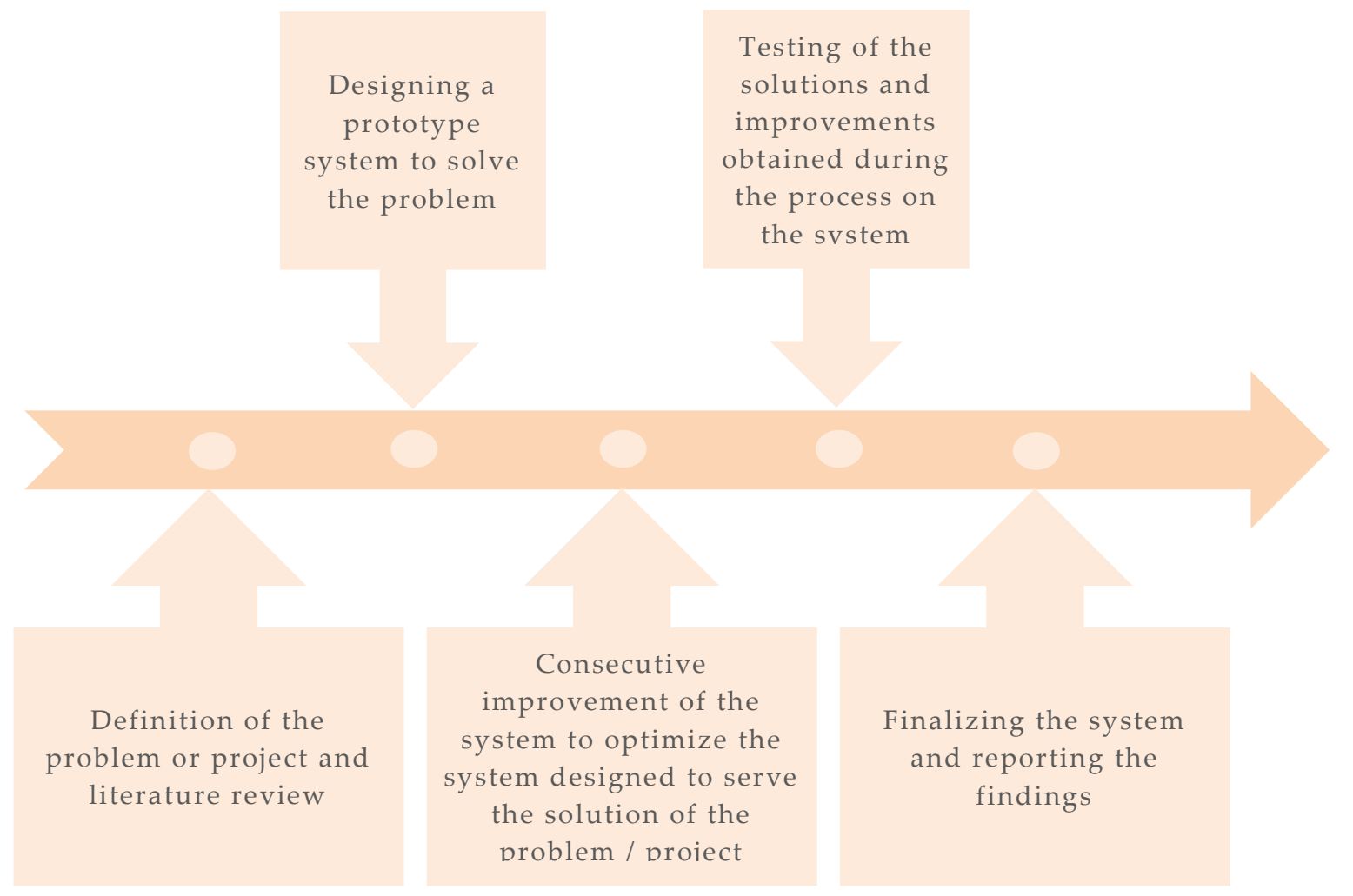

Figure 1. Process steps followed during research

\section{Data Collection Tools}

Observational and control form that were developed by researchers were used as data collection tools throughout the study. This form is one that writes the decisions for improving students' opinions and the result of discussions for design. These decisions are allocated to the group as missions and controlled in the following week. During these controls, what was identified was whether the group members completed the tasks or not and if they did, whether they had the desired result or not and whether there was any other task to be completed in the following week. In a nutshell, the process of project development and improvement is recorded cyclically in detail with the help of this form. The ultimate version of this form is included in Appendix 1. 


\section{Findings}

One of the projects that were developed within the scope of the study carried out in this section was revealed down to the last detail. Design and development process of relevant project was focused on and the process was described in detail within the context of DBR. Mobile application, 'Which one is your choice?' that was developed by the group called G-5 was chosen as the sample project.

General information about mobile application 'Which one is your choice?'

The aim of this project was to design and develop a social media application. This mobile application "Which one is your choice?" was developed for mobile devices with Android OS. The main purpose of the project is to develop an application that will help users decide when they are indecisive and cannot make a proper choice. Users may behave indecisively while buying any kind of product or choosing what to wear. In this case, the user may put this to the vote through forming a survey with pictures on the application. The users can learn the ideas of their friends and other users thanks to this survey. The results of the survey may help users decide. This application has been developed with Android Studio development environment. Software life-cycle stages of this project, which was developed in accordance with Mobile-D agile software development method, was reported by project team in detail.

Findings related to mobile application 'Which one is your choice?'

The design of 'Which one is your choice?' mobile application began with registration page. In Figure 2, images of registration were given. In the third week, first screenshot related to design in Figure 2.a was discussed and ultimate version was obtained in Figure 2.b in accordance with decisions that were taken during the session.

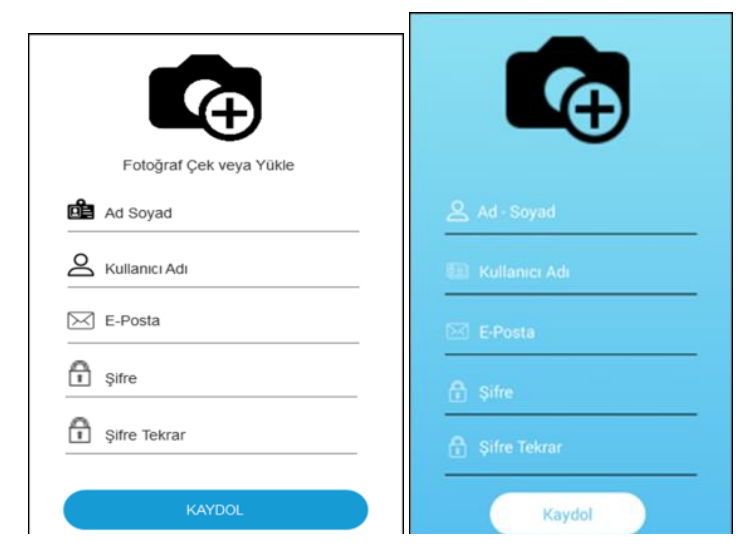

Figure 2. (a) First version (b) last version of application's user registration screenshot 
Users can register to the application by filling the spaces on registration screenshot. Profile picture can be added to application by clicking photography symbol or taking photograph via camera. After filling the spaces on registration screenshot, registration is finished with 'Register' button. Dialogues related to discussions about the first design of user register interface of students are as follows:

Std2: ...It seems beautiful, generally. But I was not sure about the color. And I think that the explanatory information below the camera picture is unnecessary, all users know what it is for, no need to write it again...

Std5: ...I agree with my friend, you can change the background color. Because the screen is completely white and the color change may create a different effect. And we can remove what it is written under icon. We can also replace first two icons in the menu. I think these would be more appropriate...

Std3: ...Then let's change the color of background with light blue and let's edit the colors of writing...

Std1: ...And that 'Register' button covers the whole screen horizontally, you can make it narrower...

Group members edited their designs in accordance with these discussions. In the following week ( $4^{\text {th }}$ week), the ultimate version of the design was formed as in Figure 2.b. Participants in this session had consensus that the registration page found its ultimate version after this editing. During the third week, students developed login interface while designing the latest version of user registration section. In this study that went on cyclically, design improvements of previous week were evaluated in the first part of sessions while discussions about newly-developed interface were made in the second part. Within this context, the first and ultimate versions of login interface design in Figure 3 were provided in this week's session. In Figure 3.a, first design screenshot of the interface that was brought into question was included, while in Figure 3.b screenshot of ultimate design that was determined in fifth week's sessions pursuant to after-session decisions was included. 


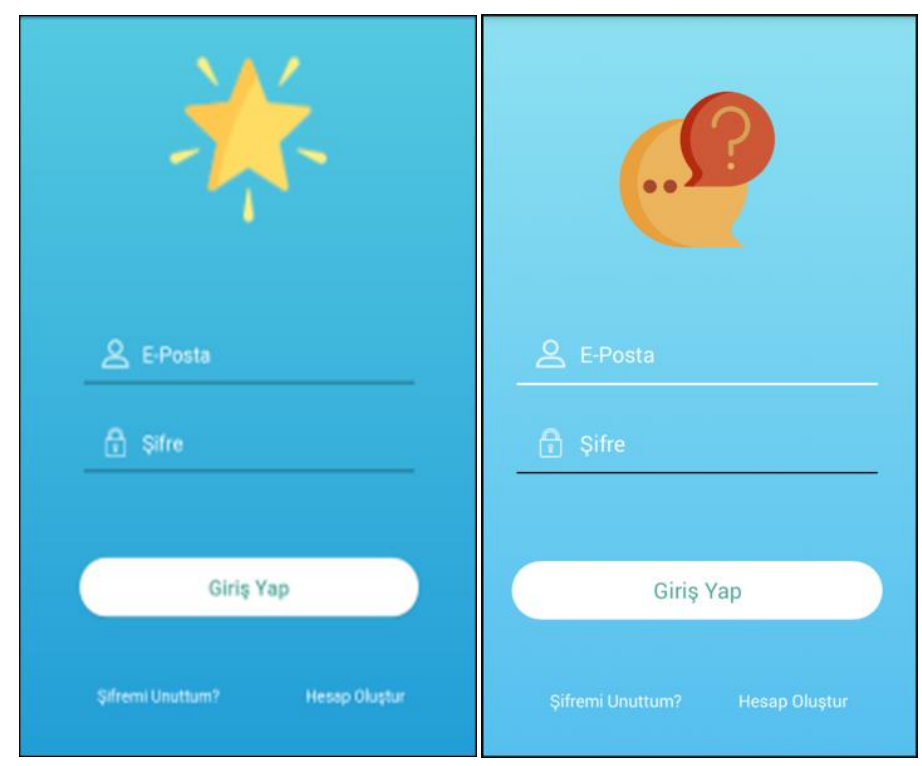

(a)

(b)

Figure 3. (a) First version (b) last version of application's user login screenshot

Users that sign up the application via the interface in Figure 3. Users can log in with e-mail and password. When users log out, they see this screen again. Dialogues related to fourth week's discussions about the first design of login interface are as follows:

Std1: ...I could not understand what the icon above the application is. What does that icon mean? To me, another icon that can be identified with the application may be designed...

Std3: ...The interface is very simple and understandable. But I think in the same way. A logo might be more meaningful...

Std4: ...And the sideline or font of the user, in whichever box helshe is, may be appear in a different color...

In the fifth week, draft design of interface related to profile pages of users that log in the application was discussed as well as accepting the interface in Figure 3.b. This interface is the one that through which users can see and change their own profile information and shares. In Figure 4, first and final versions of user profile interface design are shown. In Figure 4.a, first design screenshot that was brought into question in fifth week is shown while in Figure 4.b, screenshot of ultimate design that was approved in sixth week according to the decisions made after the sessions is given. 


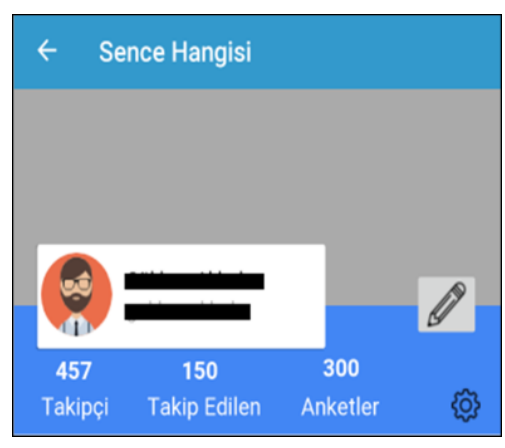

(a)

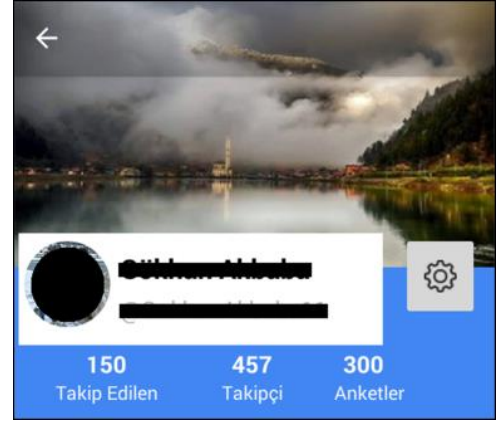

(b)

Figure 4. (a) First version (b) last version of application's user profile screenshot

Dialogues related to students' discussions on first design of login interface are as follows:

Std3: ...I think there is no need to 'Which one is your choice?' expression to appear on the screen. It may be removed...

Std4: ...I agree with my friend's idea. And the band above can also be removed. A complete picture may be embedded in the background. Or the band above may be transparent. And this sign of pen is also unnecessary. Both edit icon and pen icon are not necessary on the screen. One of them is enough...

Std2: ... The fonts of expressions like 'follower' and 'followed' under profile picture can be scaled down...

In the first part of sixth week's session, ultimate version in Figure 4.b was approved. In the second part, students brought the draft version of menu page in Figure 5.a into discussion. The user that logs in application sees the screen shown in Figure 5.a as menu screen. Thanks to this menu, the user may access to his/her own profile, find friends, adjust notices and log out.

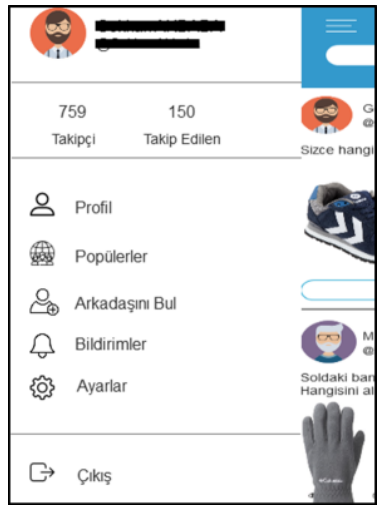

(a)

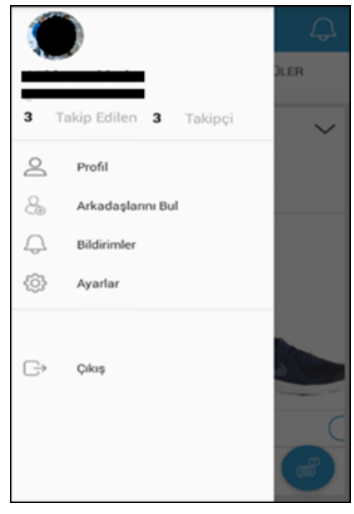

(b)

Figure 5. (a) First version (b) last version of application's menu page screenshot 
In the second part of sixth week's session, draft version of menu design in Figure 5.a was discussed. Dialogues in these discussions are as follows:

Std5: ...This page is like summarizing menu configuration of the application. I think we should take the information next to profile picture under the picture. And do you mind scaling down the expressions and numbers of 'follower' and 'followed'?...

Std1: ...I agree with my friend's opinion. And moreover, background color of the page may be changed or else blurred. Like this, the image of the page will be more beautiful. Shift between pages may be the same way...

Std3: ... There are subheads related to settings in the menu page. That's why I think 'Popular' link should better be removed...

Std2: ...I agree with my friend. This heading may be removed. And fonts of the links and font sizes may be changed. They are too big...

The ultimate design in Figure 5.b was approved in the first part of seventh week's session. And image of application's home page screenshot in Figure 6.a was brought into question in the second part of the session. The user who successfully signs in and logs in for the first time or logs in anytime will see the screen in Figure 6.a. When the user wants to vote for the posts that he/she views, he/she can click the star button on the screen and the button becomes yellow. With the yellow button, the user means having voted the post. The results of voting are viewed in the small blue flat shown on the screen.

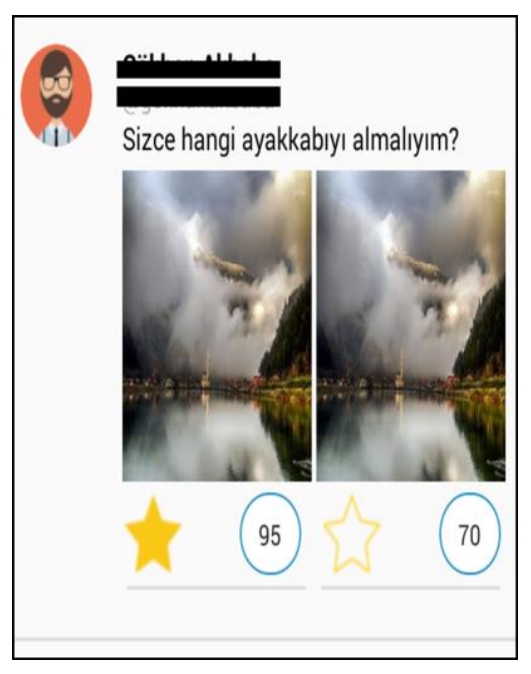

(a)

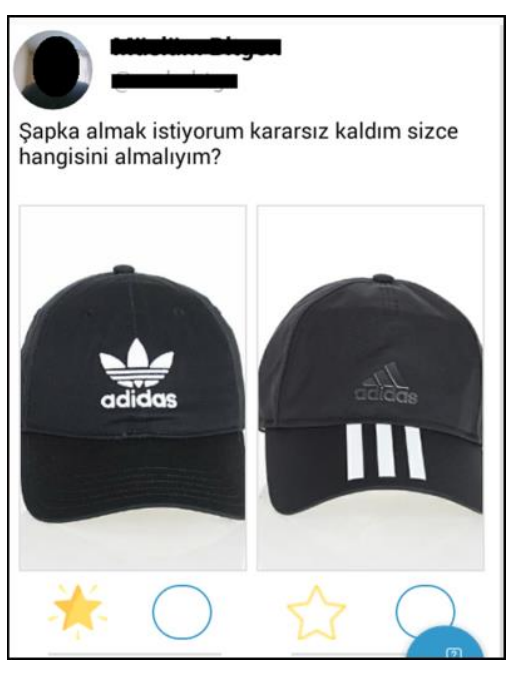

(b)

Figure 6. (a) First version (b) last version of application's home page screenshot 
Dialogues about the discussions in seventh week are as follows:

Std6: ...Home page is simple and beautiful... But yellow star may be more

attractive...

Std3: ... This design is enough to me...

Std4: ... Would not it be better to frame the pictures on the screen?...

In the eighth week, screenshot of home page, which was the last screenshot interface of the application and shown in Figure 6.b., was approved. And ultimate version of developed mobile application was thus decided and the project was completed successfully.

\section{Discussion and Conclusions}

Throughout this study, a research in accordance with DBR was carried out within the scope of Final Project course that belongs to Software Engineering Department. Development processes of software projects that were designed and developed within the scope of this course were sustained based on DBR. All processes of one application that was chosen randomly were reported within the scope of the study. In the development of this mobile application, 'Which one is your choice?', mobile-D agile model was grounded. Observational method and control form that were developed by researchers as data gathering tools in the implementation were utilized. Via this form, necessary improvements were practiced on the implementation through using collected qualitative data in designing stage. Improvements that were made the product appear in this cyclical process were reflected on the design.

DBRs are especially preferred to deal with and solve the problems of design in studies aimed at product development (Kuzu et al, 2011). From this perspective, design problems in implementations pursuant to DBR were handled by shareholders and solutions were offered to manage them. In addition to many research methods especially experimental ones in educational studies, DBR is used effectively in these studies just to solve the problems that cannot be tackled (Kuzu et al, 2011). When viewed the studies throughout the literature, we can mention the studies, which express that the reflection of students' ideas, the target audience, on design process increase the quality of the design and process of it (Coşkundere \& Erişti, 2017; Kuzu et al., 2011). The result of this study can be said to yield such a result. Throughout the study, shareholders exchanged their views and improvements 
were reflected on the design accordingly. Within the literature, it is expressed that collaboration of researchers and participants make researchers gain important experiences (Baltaci et al., 2016). When viewed from this perspective, co-working in this study can also said to contribute to better designs since the students made the first version of their designs and asked the opinion of other participants about this design. Certain decisions for improving design in the sessions where these opinions are discussed were made. Moreover, results of this study are important in that they point to a potential for various experiences that students will gain with the help of this method in the courses aimed at a project or product. In these courses, design processes become important, which make design-based researches necessary (Kuzu et al., 2011). When considered that the core philosophy of DBRs is engineering process (Aşık \& Yılmaz, 2017; Ercan \& Şahin, 2015), this kind of researches are probable to contribute to learning experience and outputs of engineering education.

The limitation of the study can be indicated as the description of design process solely. Throughout the study, implementation process within the scope of final project course of only DBR was reported in detail. In the future studies, effects of these processes on students' individual and professional developments and learning experiences may be researched. With the help of these studies, reflections of DBRs on engineering education in general and software engineering education in particular may be revealed at large.

\section{References}

Amiel, T., \& Reeves, T. C. (2008). Design-based research and educational technology: Rethinking technology and the research agenda. Educational Technology \& Society, 11(4), 29-40.

Anderson, T., \& Shattuck, J. (2012). Design-based research a decade of progress in education research?. Educational Researcher, 41(1), 16-25.

Aşık, G., \& Yılmaz, Z. (2017). Design-based research and teaching experiment methods in mathematics education: Differences and similarities. Journal of Theory and Practice in Education, 13(2), 343-367.

Baltacı, S., Yıldız, A., Kıymaz, Y., \& Aytekin, C. (2016). Reflections from a design based research preparing GeoGebra supported activities towards gifted students. Mehmet Akif Ersoy University Journal of Education Faculty, 1(39), 70-90.

Barab, S., \& Squire, K. (2004). Design-based research: Putting a stake in the ground. The Journal of Learning Sciences, 13(1), 1-14. 
Brown, A.L. (1992). Design experiments: Theoretical and methodological challenges in creating complex interventions in classroom settings. Journal of the Learning Sciences, 2(2), 141-178.

Collins, A., Joseph, D., \& Bielaczyc, K. (2004). Design research: Theoretical and methodological issues. Journal of the Learning Sciences, 13(1), 15-42.

Coşkunserçe, O., \& Erişti, S. D. B. (2017). Development of an online orientation system for international students' cultural adjustment process through design based research methodology. Educational Technology Theory and Practice, 7(1), 83-104.

Dönmez, O, Yaman, F, Şahin, Y, \& Kabakçı-Yurdakul I (2016). Developing mobile applications for hearing-impaired: Wheel of fortune. Educational Technology Theory and Practice, 6(1), 22-41

Ercan, S., \& Şahin, F. (2015). The usage of engineering practices in science education: Effects of design based science learning on students' academic achievement. Necatibey Faculty of Education Electronic Journal of Science and Mathematics Education, 9(1), 128-164.

Jollands, M., Jolly, L., \& Molyneaux, T. (2012). Project-based learning as a contributing factor to graduates' work readiness. European Journal of Engineering Education, 37, 143-154.

Kuzu, A., Cavkaytar, A., Çankaya, S., \& Öncül, N. (2013). Participants' views about mobile skill teaching software developed for parents of individuals with intellectual disability. Anadolu Journal of Educational Sciences International, 3(2), 1-21.

Kuzu, A., Çankaya, S., \& Misırlı, Z. A. (2011). Design-based research and its implementation in the design and development of learning environments. Anadolu Journal of Educational Sciences International, 1(1), 19-35.

Lesh, R., \& Sriraman, B. (2005). Mathematics education as a design science. ZDM, 37(6), 490505.

McKenney, S., \& Reeves, T. C. (2013). Systematic review of design-based research progress: Is a little knowledge a dangerous thing?. Educational Researcher, 42(2), 97-100.

Mills, J. E., \& Treagust, D. F. (2003). Engineering education - Is problem-based or projectbased learning the answer?. Australasian Journal of Engineering Education, 3(2), 2-16.

Özyurt Ö., \& Özyurt H. (2017). Design-based research and applicability in software engineering education, I. International Turkish World Engineering and Science Congress, Antalya, Turkey.

Reeves, T. C. (2000). Enhancing the worth of instructional technology research through "design experiments" and other development research strategies. International perspectives on instructional technology research for the $21^{\text {st }}$ century, New Orleans, LA, USA.

Sandoval, W. A., \& Bell, P. (2004). Design-based research methods for studying learning in context: Introduction. Educational psychologist, 39(4), 199-201.

Tural-Sönmez, M. (2017). Matematiksel modelleme problemlerinin yapılandırılması üzerine tasarım tabanlı inceleme: finansal içerik örneği [Design based Investigation on construction of mathematical modelling problems: example of financial content]. Journal of Computer and Education Research, 5(10), 218-240. 
Wang, F., \& Hannafin, M.J. (2005). Design-based research and technology-enhanced learning environments. Educational Technology Research and Development, 53(4), 5-23.

Yaman, F., Dönmez, O., Avc1, E., \& Yurdakul, I. K. (2016). Integrating mobile applications into hearing impaired children's literacy instuction. Education and Science, 41(188), 153-174.

Yıldirım, G. (2014). Enrichment prosess of e-books intended for tablet computers with video: A design based research. (Unpublished PhD Thesis). Atatürk University, Erzurum.

Zhou, C. (2012). Integrating creativity training into problem and project based learning curriculum in engineering education. European Journal of Engineering Education, 37, $488-499$. 